\title{
8
}
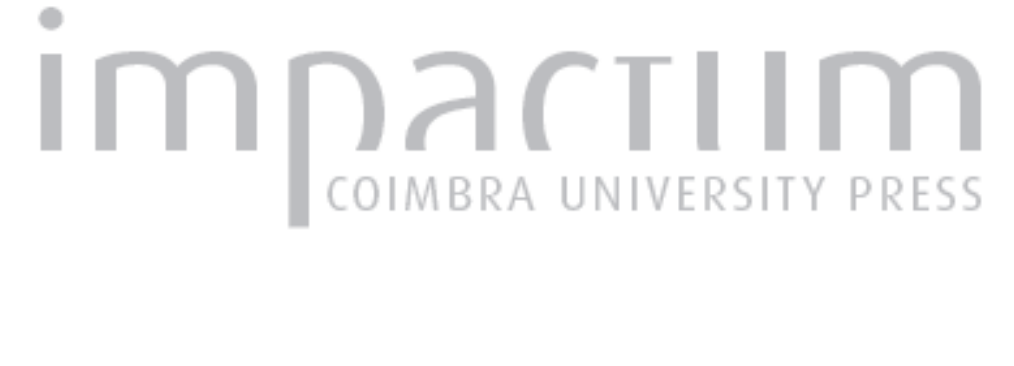

\section{Impactos hidrometeóricos no alfa do Pantanal sul-mato-grossense/Brasil}

Autor(es): $\quad$ Fernandes, Elvira Fátima de Lima; Anunciação, Vicentina Socorro

Publicado por: Imprensa da Universidade de Coimbra

URL persistente:

URl:http://hdl.handle.net/10316.2/43269

DOI:

DOI:https://doi.org/10.14195/1647-7723_25-1_2

Accessed : $\quad$ 26-Apr-2023 12:27:24

A navegação consulta e descarregamento dos títulos inseridos nas Bibliotecas Digitais UC Digitalis, UC Pombalina e UC Impactum, pressupõem a aceitação plena e sem reservas dos Termos e Condições de Uso destas Bibliotecas Digitais, disponíveis em https://digitalis.uc.pt/pt-pt/termos.

Conforme exposto nos referidos Termos e Condições de Uso, o descarregamento de títulos de acesso restrito requer uma licença válida de autorização devendo o utilizador aceder ao(s) documento(s) a partir de um endereço de IP da instituição detentora da supramencionada licença.

Ao utilizador é apenas permitido o descarregamento para uso pessoal, pelo que o emprego do(s) título(s) descarregado(s) para outro fim, designadamente comercial, carece de autorização do respetivo autor ou editor da obra.

Na medida em que todas as obras da UC Digitalis se encontram protegidas pelo Código do Direito de Autor e Direitos Conexos e demais legislação aplicável, toda a cópia, parcial ou total, deste documento, nos casos em que é legalmente admitida, deverá conter ou fazer-se acompanhar por este aviso.

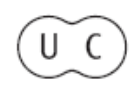


territorium/25w|.

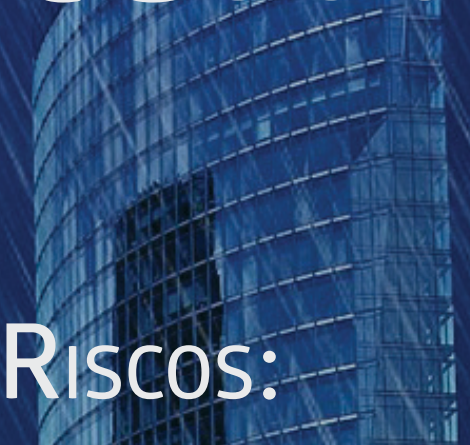

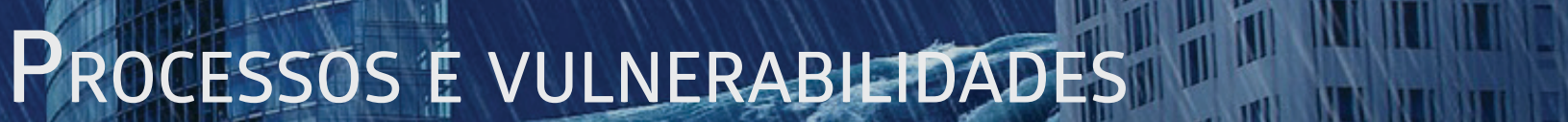

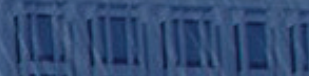
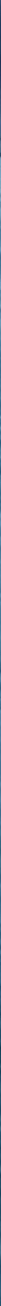

Imprensa da Universidade de Coimbra

Associação Portuguesa de Riscos, Prevenção e Segurança

2018 


\title{
IMPACTOS HIDROMETEÓRICOS NO ALFA DO PANTANAL SUL-MATO-GROSSENSE/BRASIL*
}

CLIMATIC HAZARD IN ALPHA OF PANTANAL SOUTH-MATO-GROSSENSE/ BRAZIL

Elvira Fátima de Lima Fernandes

Universidade Federal de Mato Grosso do Sul (Brasil) elviraftf@gmail.com

Vicentina Socorro da Anunciação

Universidade Federal de Mato Grosso do Sul (Brasil) vique56@hotmail.com

\begin{abstract}
RESUMO
O alfa do Pantanal sul-mato-grossense brasileiro vem sendo atingido por inundações sucessivas na década de 2010. 0 objetivo do trabalho foi analisar a espacialização dos impactos hidrometeóricos que ocorreram nos últimos sete anos nas sedes municipais de Aquidauana e Anastácio, com ênfase no episódio de 2011, para relacionar a função urbana estabelecida na área suscetível à inundação com a intensidade das inundações sazonais. A pesquisa fundamentou-se no entendimento das variáveis consideradas na área estudada, informações socioeconômicas e inventariação dos lotes. 0 trabalho de campo contou com um pré-mapeamento que consistiu no reconhecimento territorial e geomorfológico da área de estudo, e posteriormente a divisão das áreas suscetíveis à inundação em cinco setores, para descrição do perímetro urbano, foram analisados os Planos Diretores. Os resultados apontam a diminuição significativa do tempo de recorrência das inundações e revelam que a intensidade de magnitude das inundações está diretamente relacionada com os excessos pluviométricos na área da bacia hidrográfica do rio Aquidauana.
\end{abstract}

Palavras-chave: Excessos pluviométricos, áreas suscetiveis, inundações, risco.

\section{ABSTRACT}

The alpha of the Brazilian Pantanal in south Mato Grosso has been hit by successive floods in the decade of 2010. The objective of this work was to analyse the spatialization of the climatic hazards that occurred in the last seven years in the municipal headquarters of Aquidauana and Anastácio, with emphasis on the episode of 2011, to relate the urban function established in the area prone to flooding with the intensity of the seasonal floods. The research was based on the understanding of the variables considered in the studied area, socioeconomic information and inventory of the land parcels. The field work had a pre-mapping that consisted of the territorial and geomorphological recognition of the study area, and later the division of the areas prone to flooding into five sectors. To describe the urban perimeter, Directors Plans were analysed. The results indicate a significant decrease in the recurrence time of the floods and show that the magnitude of the floods is directly related to the rainfall excess in the area of the Aquidauana river basin.

Keywords: Excess rainfall, susceptible areas, flooding, risks.

\footnotetext{
* O texto deste artigo foi submetido em 30-06-2016, sujeito a revisão por pares a 02-09-2016 e aceite para publicação em 20-06-2017.

Este artigo é parte integrante da Revista Territorium, n. ${ }^{\circ} 25$ (I), 2018, ${ }^{\circ}$ RIscos, ISSN: 0872-8941.
} 


\section{Introdução}

Episódios climáticos extremos têm desencadeado riscos hidrológicos. A sua materialização apresenta maior visibilidade nos espaços urbanos repercutindo-se nas inundações, relacionadas ao subsistema hidrometeórico. Os problemas referentes à dinâmica atmosférica afetam de maneira sistemática os espaços urbanos, e condizem principalmente com a ocupação indevida de encostas e fundos de vales, aspectos cada vez mais perceptíveis em áreas com grande concentração populacional. " $O$ espaço urbano desordenado resulta do/no mau uso da terra, que por sua vez, implica na formação de áreas de risco, que serão ocupadas principalmente pela população com menor poder aquisitivo, logo a população mais vulnerável" (T. Hoffmann et al., 2014, p. 224).

Tem-se observado que nos centros urbanos ocorreram alterações das características originais no processo de ocupação do solo, na pluralidade, de forma negligente e discriminatória, frente à intensa concentração dos aglomerados humanos. T. Lucas et al., (2015, p. 8), referindo-se à realidade urbana no Brasil afirmou que "as populações de baixa renda são as mais vulneráveis às enchentes, enxurradas, alagamentos e outros processos devido à ocupação irregular em áreas geologicamente desfavoráveis".

No caso do território brasileiro, a proximidade com a linha do Equador potencializa a atuação das massas de ar equatoriais e tropicais (Ea = Equatorial Atlântica; Ec = Equatorial Continental; $\mathrm{Ta}=$ Tropical Atlântica; $\mathrm{Tc}$ = Tropical Continental) no país e, principalmente, as regiões nordeste, sudeste e sul são castigadas todos os anos por impactos hidrometeóricos. Entende-se impacto como "[...] episódios ou eventos restritos no tempo que estão presos ao modo de transmissão de energia, ou seja, ao ritmo de sucessão dos estados atmosféricos" (C. Monteiro, 2015, p.119).

A mídia volta a atenção da abordagem temática para os grandes centros como Pernambuco, Rio de Janeiro, São Paulo, Santa Catarina, porém a realidade imprime reflexos em outras localidades como nas regiões Norte e Centro-Oeste brasileiras.

O Estado de Mato Grosso do Sul, localizado na parte ocidental da região Centro-Oeste, foi constituído no final da década de 1970. O intuito era de interiorizar o desenvolvimento nacional, reduzir os vazios demográficos, apoiar e potencializar novas fronteiras de produção agropecuária e agroindustrial no cerrado do oeste brasileiro.

O crescimento demográfico foi intenso em algumas áreas e ampliaram-se acentuadas modificações no espaço geográfico, a partir da atuação de programas de incentivos à agropecuária como: o
POLOCENTRO (Programa de Desenvolvimento das Áreas de Cerrado), o PRODEGRAN (Programa de Desenvolvimento da Região da Grande Dourados) e o PRODEPAN (Programa de Desenvolvimento da Região do Pantanal) (A.Duarte, 1989).

A emigração foi muito acentuada na década de 1980, principalmente por gaúchos e paranaenses que cobiçavam ampliar as áreas de produção, colaborando, dessa maneira, com o adensamento populacional em áreas de risco, aumentando consideravelmente a vulnerabilidade das comunidades expostas aos hazards naturais (I. Alcántara-Ayala, 2002; C. Zamparoni e L. Nunes, 2012; D. Alexander, 2013).

Essas intervenções sistemáticas influenciaram na sustentabilidade do sistema, desencadeando riscos, dilemas ambientais e repercutindo negativamente nas áreas urbanas, quando atingidas por extremos climáticos.

Os riscos e repercussões de "meteoros de impacto" (C. Monteiro, 2015, p.88) também são sentidos no alfa do Pantanal sul-mato-grossense. "Inundações periódicas vêm se apresentando com relevância na cidade de Aquidauana ( $55^{\circ} 78^{\prime} \mathrm{W}$; $20^{\circ} 46^{\prime}$ 'S) e em menor intensidade

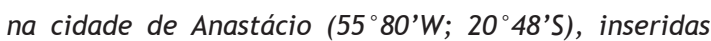
na fisionomia Depressão Aquidauana - Bela Vista $e$ em territórios que margeiam o rio Aquidauana" (E. Fernandes et al., 2015, p. 182).

Entre os anos de 2010 e 2016, sucederam-se no sítio urbano de Aquidauana e Anastácio seis episódios de transbordamentos, que variaram conforme a intensidade de magnitude. As inundações do mês de março de 2011, abril de 2013 e janeiro de 2016 foram diagnosticadas como um "subsistema hidrodinâmico" (C. Monteiro, 2015, p.125). Estes eventos perturbaram, "sensivelmente, as formas de circulação e comunicação internas e ligação externa” (C. Monteiro, 2015, p. 119). Dezenas de pessoas ficaram desabrigadas, centenas desalojadas e houve avultados danos ambientais e prejuízos econômico-sociais (fot. 1 e fot. 2).

No evento adverso, que se iniciou em 28 de fevereiro e se estendeu até 09 de março de 2011, a cidade de Aquidauana ficou estática por quinze dias consecutivos. Ocorreu racionamento de combustível e alimentação, uma vez que a Ponte Coronel Antônio Ignácio Trindade (Nova), a Ponte Roldão Carlos de Oliveira (Velha) e a Ponte Boiadeira, que interligam as cidades vizinhas, ficaram interditadas, por conta da grande vazão de água que transbordou da calha, atingiu os terraços do canal e ocupou a extensão máxima do leito excepcional. Na ocasião foi aferida uma área total, na sede municipal de Aquidauana, de aproximadamente $611.214,50 \mathrm{~m}^{2}$, atingindo trinta e quatro quadras, e na sede de Anastácio, a área total é de 527.407,64 $\mathrm{m}^{2}$ afetando diretamente aproximadamente dezoito quadras. 

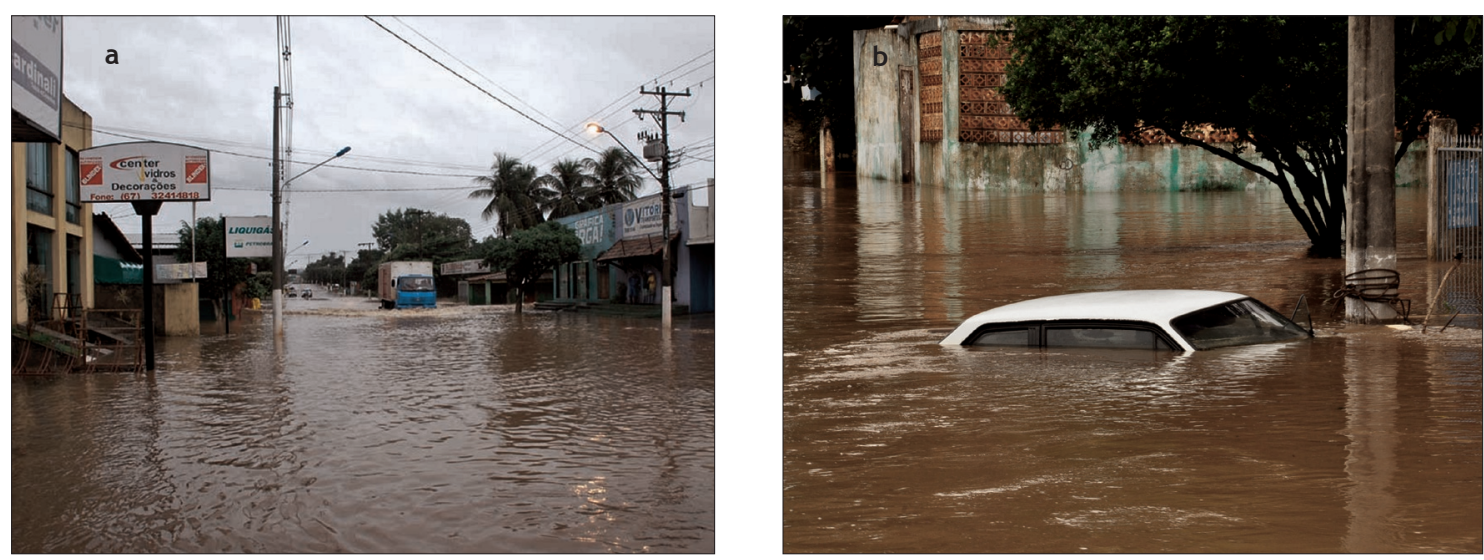

Fot. 1 - Inundação de impacto hidrometeórico em Aquidauana, 2011: a) Rua Teodoro Rondon no centro da cidade. b) cruzamento das ruas Cândido Mariano e Manoel Aureliano da Costa, bairro Guanandy (Fonte: Arquivo pessoal da família Moro, 2011).

Photo 1 - Climatic hazard of flooding in Aquidauana, 2011: a) Teodoro Rondon street in the city centre b) on the corner of Cândido Mariano and Manoel Aureliano da Costa, Guanandy district (Source: Personal archive of the Moro family, 2011.
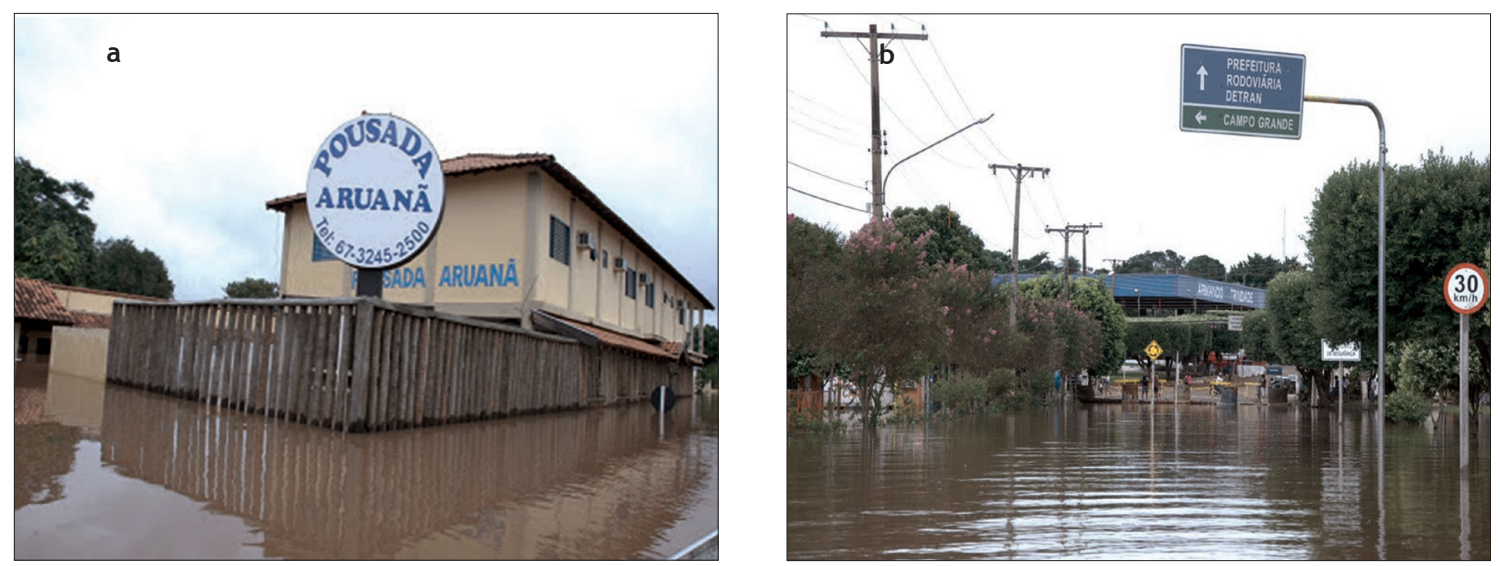

Fot. 2 - Inundação de impacto hidrometeórico em Anastácio, 2011: a) Pousada na travessa Anderson. b) Rodoviária na área central (Fonte: Arquivo pessoal da família Moro, 2011).

Photo 2 - Climatic hazard of flooding in Anastácio, 2011: a) inn on the Anderson small street. b) bus station in the central area (Source: Personal archive of the Moro family, 2011).

Devido à predisposição geomorfológica da área, moradores e comerciantes que se estabelecem na planície de inundação, uma vez que de um modo genérico, a planície de inundação pode ser definida como uma faixa de terreno relativamente plano, margeando um curso d' água, formada por sedimentos transportados pelo escoamento e inundada regularmente com o aumento do nível da água no rio (J. Manning, 1997), estão expostos a riscos hidrológicos recorrentes, sempre que o escoamento superficial sofre alteração, ocasionada pela intensidade da chuva sobre a bacia hidrográfica do rio Aquidauana.

Este trabalho teve como objetivo a ampliação da percepção do risco em áreas sujeitas à inundação, através da espacialização dos impactos hidrometeóricos que ocorreram nos últimos sete anos nas sedes municipais de Aquidauana e Anastácio, com ênfase no episódio de 2011. Pretendeu-se relacionar a função urbana estabelecida nas áreas de suscetibilidade à inundação com a intensidade das inundações sazonais.

\section{Metodologia}

A pesquisa fundamentou-se no entendimento das variáveis consideradas na área estudada. Para a análise, foram apreciados os dados do Instituto Brasileiro de Geografia e Estatística (IBGE, 2010), nomeadamente, informações socioeconômicas, disponibilidade de serviços e equipamentos urbanos (como escolas, postos do programa saúde da família (PSF), locais de lazer, entre outros) e elementos relacionados à infraestrutura (como saneamento básico, pavimentação, condições 
gerais do sistema viário e disponibilidade de transporte). Foram também considerados estudos já realizados na área suscetível a impactos hidrometeóricos da cidade de Aquidauna (E. Artigas et al., 2012; P.Joia e V. Anunciação, 2013; E. Fernandes et al., 2015).

Seguindo as recomendações do Ministério das Cidades, que acatou o conjunto de medidas preconizadas pelo Instituto de Pesquisas Tecnológicas - IPT (MINISTÉrIO DAS CIDADES [MCID], 2006, 2007), o trabalho de campo contou com um pré-mapeamento, que consistiu no reconhecimento territorial e geomorfológico da área de estudo. Nessa etapa, também foram coletados pontos representativos para o estudo com registros fotográficos.

A delimitação da área de estudo foi efetuada a partir de visitas de campo. Foram mapeadas as zonas sujeitas a impactos hidrometeóricos (inundações) e os limites do curso d’água dentro do perímetro urbano.

Para descrição do perímetro urbano, foram analisados os Planos Diretores de Anastácio (Plano Diretor, 2006) e Aquidauana (Plano Diretor, 2008), Planta Cadastral das duas cidades e legislação sobre limite dos bairros (Prefeitura de Aquidauana, 2015).

Localizaram-se cinco áreas suscetíveis às inundações sazonais (fig. 1). Em Aquidauana, as parcelas dos bairros Guanandy (1) e Centro (2) e em Anastácio, as parcelas da Vila Santos Dumont (1), Centro (2) e Vila Afonso Paim (3) (fig. 1).
A delimitação de suscetibilidade foi realizada após uma compilação de observação sobre a descaracterização da vegetação natural (Governo Federal, 2012), dados climáticos e hidrológicos (ANA, 2016), fatores geológicos e geomorfológicos (G. Guidicini e C. Nieble, 1976) e baixa declividade dos terrenos (J. Olcina Campos et al., 2010). Realizou-se também um pré-mapeamento, que consistiu no reconhecimento territorial da área de estudo, acatando as considerações de informações geográficas, do Instituto de Pesquisas Tecnológicas Brasil - IPT propostas em conjunto com o Ministério das Cidades (MINISTÉRIO DAS CIDADES [MCID], 2007).

\section{Caracterização do uso das bordas do rio Aquidauana}

Para alcançar os objetivos traçados foram realizadas vistorias das margens do rio Aquidauana e inventariação de todos os lotes existentes na área de estudo. Houve uma pré-delimitação dos locais, realizada através de imagens da plataforma Google Earth (2014), na qual a planície de inundação (margens esquerda e direita) foi dividida em setores, ou seja, cinco zonas sujeitas à inundação (fig. 1).

Para a inventariação dos lotes foram realizadas anotações sobre cada tipo de função urbana por meio de siglas predeterminadas, no mapa de cadastro urbano. Os dados levantados no trabalho de campo foram organizados na planilha Excel 2010, a fim de se estabelecer uma classificação de uso da terra nas

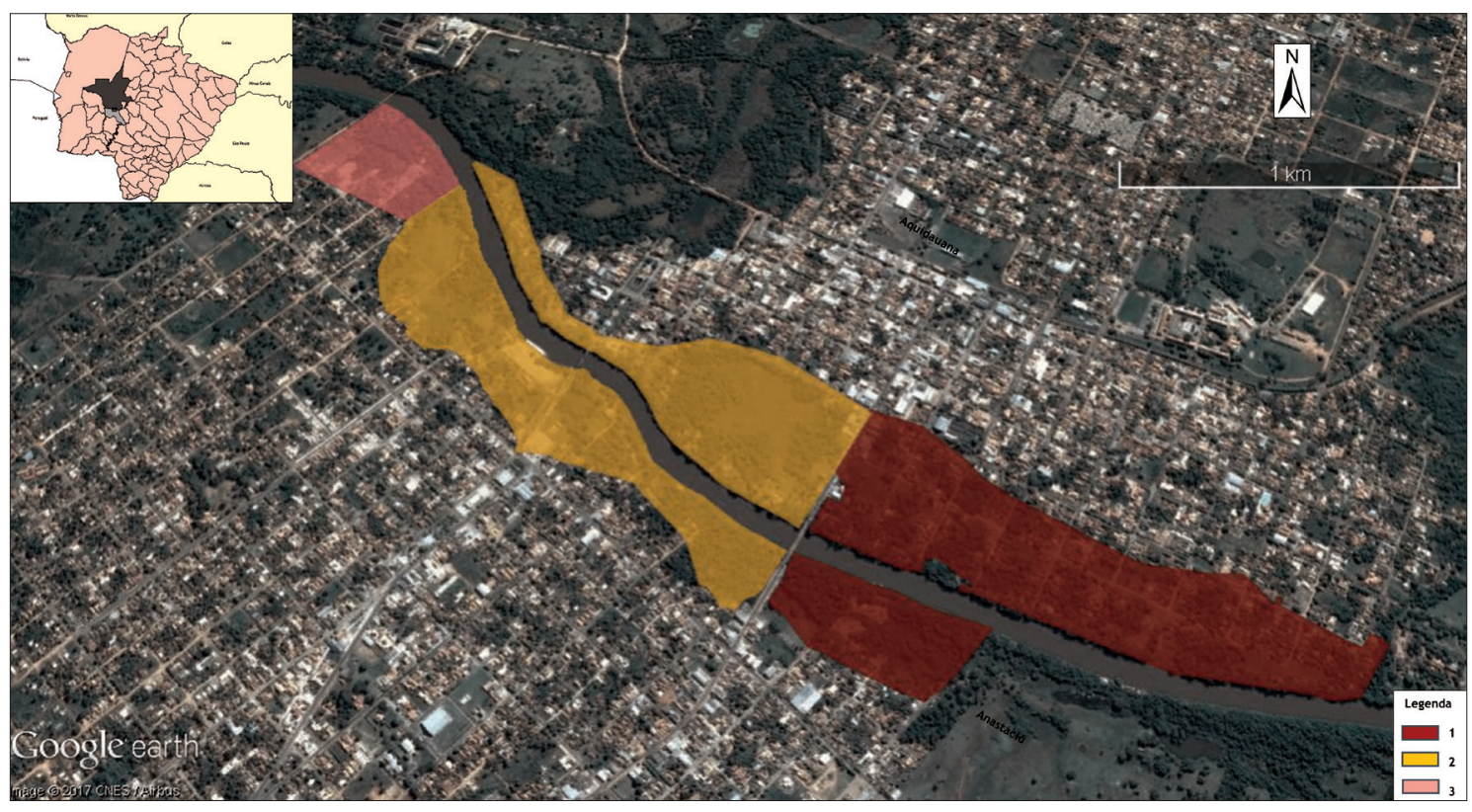

Fig. 1 - Áreas suscetíveis à inundação: 1) Guanandy (Aquidauana) e Vila Santos Dumont (Anastácio); 2) Centro; 3) Vila Afonso Paim (Fonte: Adaptado pelas autoras de Google Earth e IBGE, 2010 a).

Fig. 1 - Areas prone to flooding: 1) Guanandy (Aquidauana) and Vila Santos Dumont (Anastácio); 2) Centre; 3) Vila Afonso Paim (Source: Adapted by the authors of Google Earth and IBGE, 2010 a). 
margens do rio Aquidauana dentro do perímetro urbano de Anastácio e Aquidauana, sendo atribuídos nomes para cada atributo relacionado.

A classificação foi estabelecida conforme a tipologia das edificações: Itha dos pescadores, residências (ocupadas, turistas, vazias, abandonadas, fechadas), atividades econômicas (comércio, serviço, areeiros) e institucionais. Os demais lotes sem edificações foram caracterizados: chácara, área úmida (Pirizal), terreno baldio, vegetação rasteira e campo de futebol.

\section{Confecção do mapeamento}

A base cartográfica referente às áreas suscetíveis à inundação nas cidades de Aquidauana e Anastácio/MS iniciou-se com a montagem de um banco de dados georreferenciado, a delimitação foi realizada através de imagens adquiridas da plataforma Google Earth.

- Na primeira etapa, shapefiles Sinopse por setores (IBGE, 2010 a) foram utilizados para delimitar as duas sedes municipais;

- Em um segundo momento, iniciou-se o mapeamento da área suscetível à inundação tendo como base o mapeamento de áreas inundáveis das cidades de Anastácio e Aquidauana (Ministério do Meio Ambiente [MMA], 1997);

- Foram realizadas as análises das cotas do rio Aquidauana por meio dos dados da estação fluvial Aquidauana ( $\mathrm{n}^{\circ}$ 66945000) disponíveis no Portal da Agência Nacional de Águas (ANA, 2014), acessados em Sistema de Informações Hidrológicas (Hidro Web) e software HIDRO 1.2 (banco de dados do tipo cliente/servidor projetado especificamente para o ambiente gráfico);

- Posteriormente, destinou-se a aferição do levantamento altimétrico, na área predisposta a impactos hidrometeóricos (inundações) e averiguação da verdade terrestre;

- Em uma segunda fase, a representação altimétrica foi produzida no software Global Mapper 13.2 (2012), de forma automática (generate watershed). Foi inserida a imagem de radar interferométrico SRTM (Shuttle Radar Topographic Mission) das sedes municipais de Aquidauana e Anastácio, com resolução espacial de 30m, da quadrícula 20_57_ZN (Valeriano, 2008), gerando a hipsometria da área de estudo. Em um segundo momento, na confecção da representação altimétrica, foram incluídas, em formato Shapefile, as delimitações das duas cidades (IBGE, 2010 a) e, posteriormente, utilizou-se a função 3D para realçar a inundação da área.

Os aspectos fisiográficos da área estudada foram analisados de acordo com as informações do GeoMS
(Governo do Estado de Mato Grosso do Sul, 2011) e da Folha Aquidauana SF.21-X-A-III Escala 1: 100.000 - DSG (Governo Federal, 1964).

\section{Classificação da intensidade de magnitude das inundações}

O nível e vazão são medidos, nessa secção transversal do rio Aquidauana, através de uma escala hidrométrica, graduada até $10 \mathrm{~m}$, instalada na estação de monitoramento Aquidauana $n^{\circ} 66945000$ (ANA), na cabeceira da Ponte Roldão Carlos de Oliveira (Ponte Velha/RN. 143.393) na cidade de Aquidauana. Estudos realizados (E. Fernandes et al., 2015, p. 179) determinaram a variação altimétrica da área estudada e preconizam que nas ocasiões em que o rio ultrapassa a cota de $8,00 \mathrm{~m}$ os transbordamentos começam a afetar a população.

A partir das visitas na área estudada, foi possível conciliar as informações dos moradores com os índices pluviométricos, a vazão e a cota do rio Aquidauana. A classificação de mensuração da magnitude das inundações (QUADRo I) foi orientada por meio dos dados coletados na Agência Nacional de Águas (ANA) da Sala de Situação (ANA, 2014), que estabeleceu a delimitação mínima para inundações de pequena magnitude, a partir de 8,00 $\mathrm{m}$ (referente às inundações que afetam moderadamente o cotidiano da população). Para magnitude excepcional, tomou-se por base inundações superiores a cota de 9,50 m (episódios que interrompem a rotina de parte significativa da sociedade).

QuAdro I - Classificação da intensidade de magnitude das inundações na área urbana das cidades de Aquidauana e Anastácio/MS.

TABLE I - Classification of the intensity of the flooding magnitude in the urban area of the cities of Aquidauana and Anastácio/MS.

\begin{tabular}{|l|c|c|}
\hline $\begin{array}{c}\text { Intensidade de magnitude } \\
\text { das inundações }\end{array}$ & $\begin{array}{c}\text { Intervalos em } \\
\text { níveis }(\mathbf{m})\end{array}$ & $\begin{array}{c}\text { Altimetria da } \\
\text { área }(\mathbf{m})\end{array}$ \\
\hline Magnitude excepcional & $>9,50$ & $142,8 / 143,6$ \\
\hline Magnitude grande & $9,15-9,50$ & $142,00 / 142,7$ \\
\hline Magnitude regular/média & $8,51-9,14$ & $141,2 / 141,9$ \\
\hline Magnitude pequena & $8,00-8,50$ & $136,8 / 141,1$ \\
\hline
\end{tabular}

Fonte/Source: E. Fernandes, 2015.

\section{Discussão e Resultados}

A influência da variabilidade climática nos episódios de impacto hidrometeóricos nas cidades de Aquidauana $e$ Anastácio/MS - Brasil

O estado de Mato Grosso do Sul se encontra numa área de transição dos climas zonais (tropicais e extratropicais), assim a dinâmica atmosférica apresenta forte irregularidade e variabilidade climática oriundas da circulação atmosférica regional (J. Zavattini, 2009). 
A excepcionalidade climática no Mato Grosso do Sul está associada ao excesso no índice pluviométrico. Esses episódios ocorrem, sobretudo, na estação do verão na região, sob a influência de um sistema de grande escala, denominada Zona de Convergência do Atlântico Sul (ZCAS), característica do período, tendo um significante papel na ocorrência de veranicos e enchentes severas.

As características do clima local apresentam indíces pluviométricos anuais na faixa de $1.400 \mathrm{~mm}$ no verão (outubro a março), com períodos sazonais definidos pelo inverno seco e verão chuvoso (fig. 2), pois se localizam no início da planície pantaneira.

As enchentes e, consequentemente, as inundações, nessa região, são características do período sazonal de maior precipitação, que, para a região, tem início na primavera e habitualmente cessa no mês de março, com o fim do verão. 0 que torna dezembro e janeiro meses propícios às inundações periódicas (J. SANT’AnNa Neto,1989).

Os estudos sobre excepcionalismos climáticos nessa região são escassos, dificultados pela ausência de informações dos órgãos públicos competentes e parceiros particulares (Fazendas). Porém, informações do boletim da Climanálise (Ministério da Ciência, Tecnologia, Inovação e Comunicações [MCT - INPE/CPTEC], 2011) revelam que no episódio de extremo climático em março de 2011 houve uma notável progressão nos índices pluviométricos no transcurso da primeira quinzena de fevereiro de 2011. Segundo informação dos pesquisadores a variabilidade atmosférica foi proveniente do deslocamento do canal de umidade proveniente da Amazônia para o sul, resultando na formação de um episódio da Zona de Convergência do Atlântico Sul (ZCAS). "A atuação da Alta da Bolívia e a formação de um episódio de ZCAS, associados aos efeitos termodinâmicos locais, também contribuíram para a ocorrência de chuvas mais acentuadas em parte do Mato Grosso e no Mato Grosso do Sul" (Ministério da Ciência, Tecnologia, Inovação e Comunicações [MCT INPE/CPTEC], 2011, p.11).

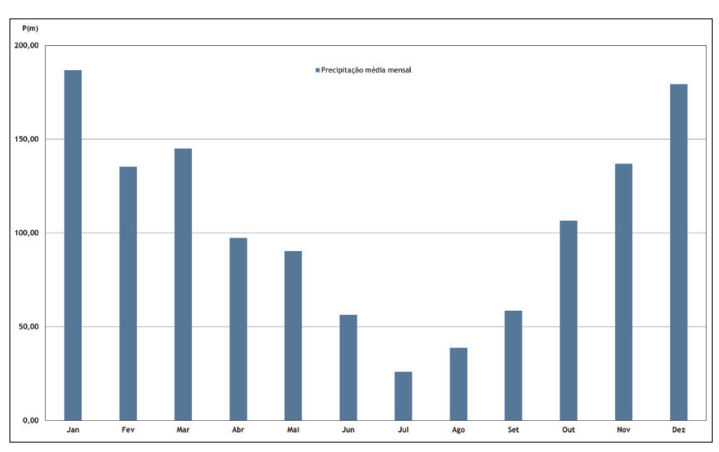

Fig. 2 - Gráfico das médias mensais de precipitação entre o período de 1978 a 2015 (Fonte: Estação Aquidauana A - 719/INMET).

Fig. 2 - Graph of monthly averages of precipitation in the period between 1978 to 2015 (Source: Aquidauana Station A - 719 / INMET).
Esporadicamente, extremos climáticos, outras sazonalidades, sentidos na região, numa junção de quatro variações - duração, tempo, intensidade e quantidade das precipitações - deflagram excessos pluviométricos, como os ocorridos nos meses de junho de 2012 e abril de 2013, ou seja, em estações atípicas, como o inverno e o outono, respectivamente.

Essa combinação de variações de duração, tempo, intensidade e quantidade das precipitações potencializa o desencadeamento da elevação das águas do rio Aquidauana, elevando a cota normal $(2,99 \mathrm{~m})$. A partir do momento em que o nível da escala hidrométrica atinge a marca de 6,21 m, a Defesa Civil considera que as duas cidades devem entrar em estado de alerta, pois há a possibilidade da população que ocupa as margens ser atingida pelos impactos hidrometeóricos.

Nos anos de 2011, 2013 e 2016 as pontes foram interditadas, porque a cota do rio Aquidauana foi superior a 9,29 m. As inundações foram consideradas de eventos extremos, seu impacto foi percebido nas duas cidades.

A influência do clima urbano nos episódios de inundação no limiar do Pantanal sul-mato-grossense necessita de estudos mais detalhados. Pesquisas específicas foram realizadas sobre o clima na cidade de Aquidauana: (V. da Silva, 2012), que estudou a temperatura do ar dentro do ambiente urbano, e a investigação sobre existência de ilha de calor (A. Honorato, 2012). Recentemente, a cidade de Anastácio também foi investigada por meio do trabalho sobre a temperatura do ar (F. Santos, 2014). Porém ainda carece de novas descobertas.

As inundações expressivas (média, grande, excepcional), entre os anos de 1976 e 2016, apresentaram intervalos que variaram entre um e sete anos (fig. 3). Porém se percebe uma mudança no ritmo das inundações do rio Aquidauana a partir da década de 2010 houve transbordamentos significativamente por cinco vezes. Foram inundações (fig. 3), de magnitude regular ou média (2010 e 2014), magnitude excepcional (2011) e grande magnitude $(2013,2016)$.

Observa-se que, na área estudada nas sedes municipais de Anastácio e Aquidauana, o intervalo das recorrências de inundações tem aumentado em virtude da dinâmica hidrológica natural que acompanhou os excessos pluviométricos na região (fig. 4).

\section{Mapeamento das áreas suscetiveis à inundação}

Segundo o estudo de Carlos Tucci (Ministério do Meio Ambiente [MMA], 1997), o período de retorno das inundações de $9,15 \mathrm{~m}$ deveria ocorrer a cada dez anos, ou seja, um índice de 10\%. Em Aquidauana e Anastácio estão ocorrendo a cada dois anos nnas últimas duas décadas. Nas seis inundações focalizadas, repetiram-se três vezes. 


\section{territorium 25 (I)}

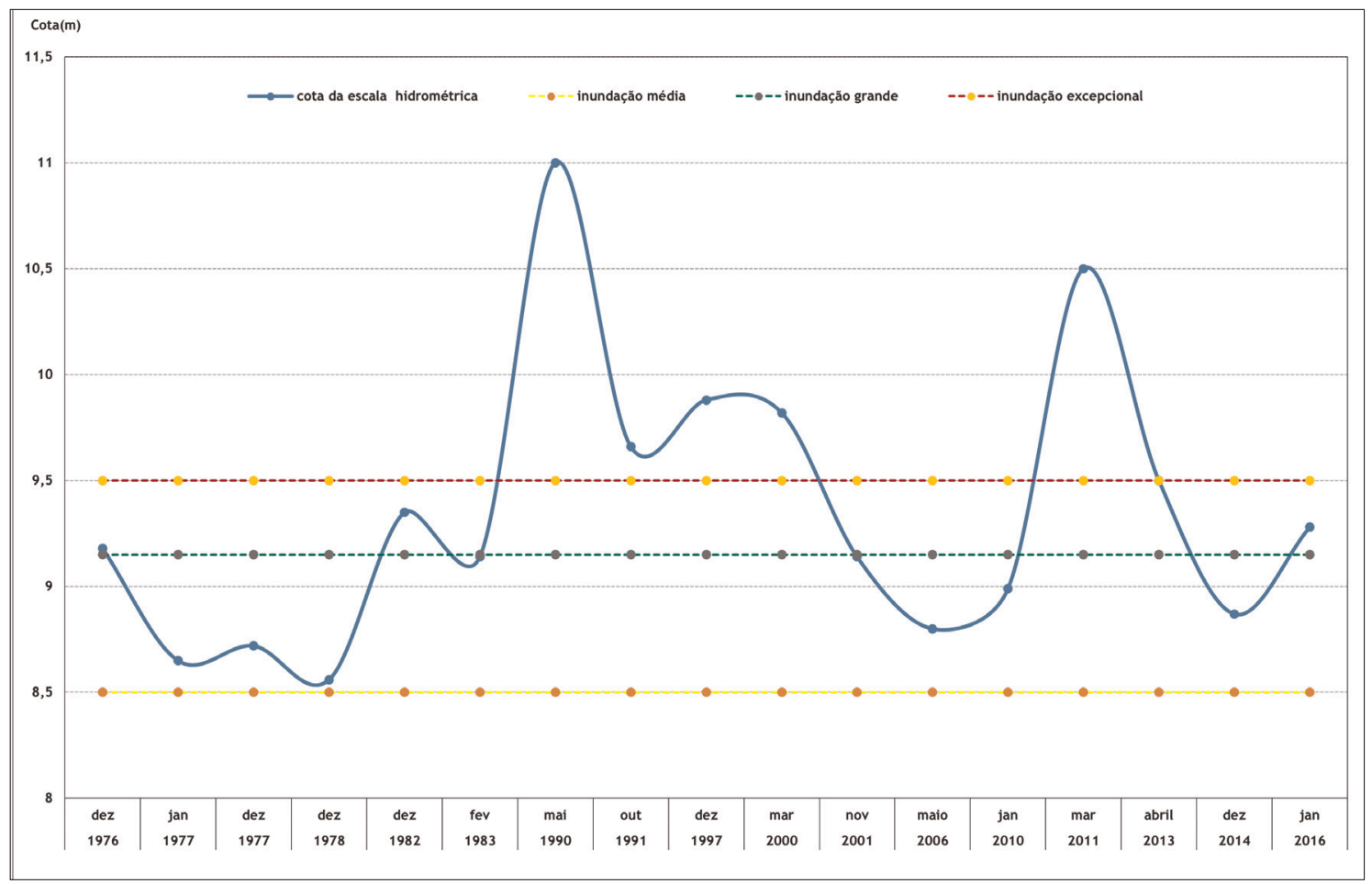

Fig. 3 - Gráfico da dinâmica hidrológica no nivel do rio Aquidauana entre 1976 e 2016 (Fonte: Hidro Web, 2016).

Fig. 3 - Graph of hydrologic dynamics of the river Aquidauana between 1976 and 2016 (Source: Hidro Web, 2016).

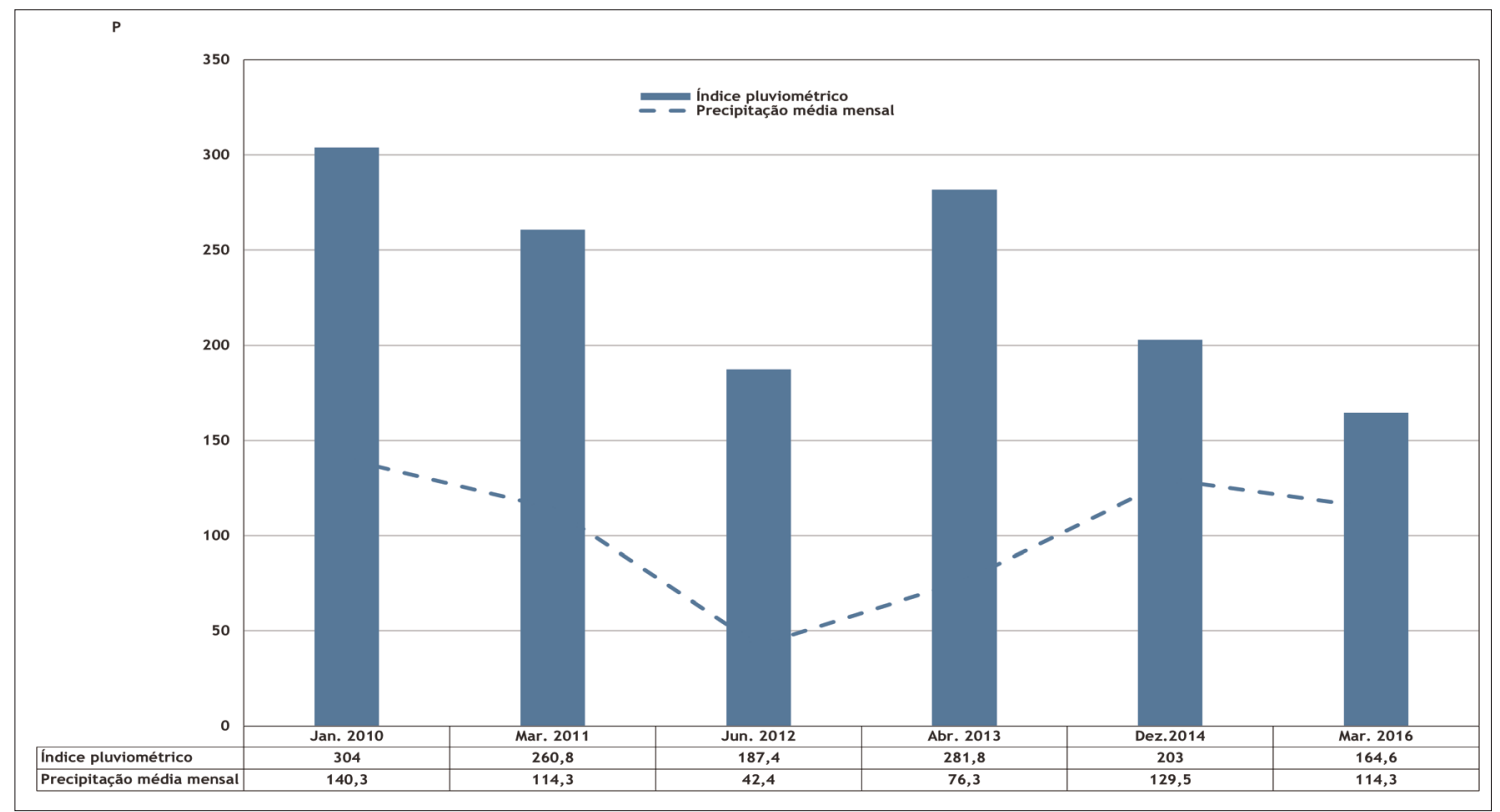

Fig. 4 - Gráfico dos excessos pluviométricos relacionados com as inundações entre os anos de 2010 e 2016 (Fonte: Estação Aquidauana A - 719/INMET).

Fig. 4 - Graph of rainfall related excesses with floods between the years of 2000 and 2016 (Source: Aquidauana Station A - 719 / INMET).

A partir dessa premissa, iniciaram-se os estudos para uma nova delimitação, visto que o nível de 9,15 m obtido para o período de dez anos se observou desde o ano de 2010, ou seja, em sete anos ele foi aferido por três vezes na escala hidrométrica instalada na Ponte Velha, próximo à Praça Nossa Senhora da Conceição, popularmente denominada por Praça da Matriz (fig. 5).

Análise multitemporal, compreendendo os anos de 1976 a 2014, realizada recentemente (E. Fernandes, 2015), 


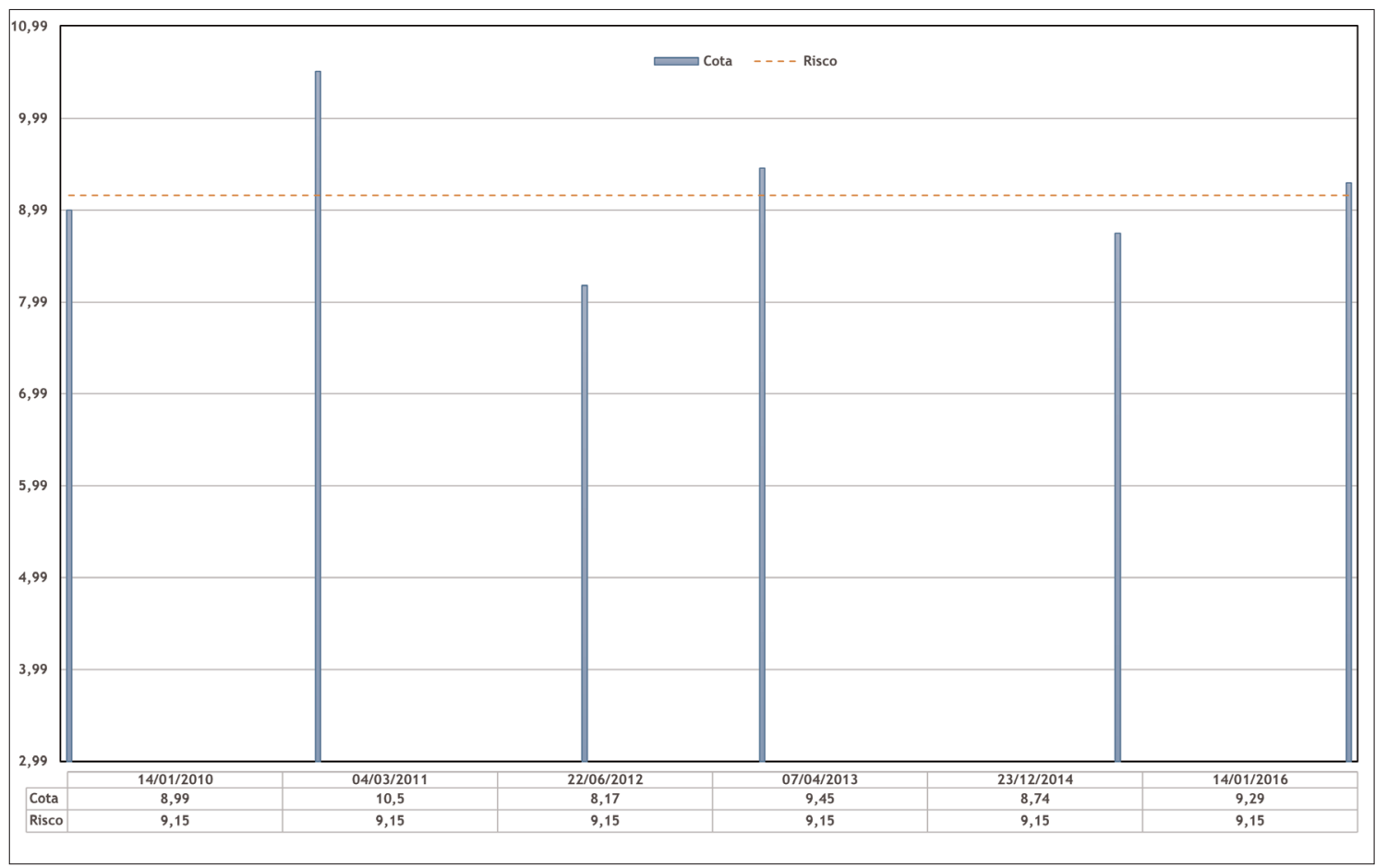

Fig. 5 - Gráfico do período de retorno das inundações entre os anos de 2010 e 2016 ( Fonte: ANA, 2016).

Fig. 5 - Graph of the period of return of the floods between the years 2010 and 2016 (Source: ANA, 2016).

aponta que a população foi atingida cinco vezes por inundações de magnitudes excepcionais, quatro de grande magnitude e oito de magnitude regular/média, totalizando dezessete episódios relevantes para população atingida. Ressalta-se que em onze vezes sucederam inundações de pequena magnitude $(8,00-8,50 \mathrm{~m})$, que trazem transtornos menores, atingindo no mínimo vinte famílias na área urbana de Aquidauana (E. Fernandes et al., 2015).

A pesquisa confirmou que o reflexo dos transbordamentos tem distribuições diferenciadas na planície de inundação nos dois perímetros urbanos analisados. A população da cidade de Anastácio encontra-se resguardada das inundações de pequena magnitude e é atingida, somente, em inundações mais expressivas, de magnitude regular/média a excepcional, por conta da altitude diferenciada nas suas margens.

A cidade de Aquidauana apresenta um fator natural determinante na frequência das inundações (J. Olcina Campos et al., 2010), que é a baixa declividade dos terrenos localizados dentro da planície de inundação, aliada a cotas altimétricas, que variam entre 136,80 e $140 \mathrm{~m}$ em relação ao nível do mar. Em inundações de magnitude excepcional como a de março de 2011 é drasticamente impactada (fig. 6).

Sendo assim, foram identificados cinco fatores que compilados contribuem para a suscetibilidade das inundações sazonais nas duas cidades:
- Fatores predisponentes (geológico, geomorfológico);

- Fator natural determinante (baixa declividade dos terrenos);

- Fatores agravantes (supressão e descaracterização da vegetação natural);

- Fator desencadeante (excesso nos índices pluviométricos);

- Fator preponderante (uso inadequado do espaço pela população).

A morfologia original antropizada em praticamente toda extensão da área estudada, o uso e ocupação da planície de inundação, com pavimentação de parte da várzea e supressão de mata ciliar, influenciam na hierarquia interna da população, primeiramente atingida em todas as recorrências de inundação (pequena, média, grande e excepcional).

Medidas de controle à inundação, que visam a minimizar os danos e prejuízos aos quais as populações atingidas são submetidas sazonalmente, podem ser classificadas em estruturais (como as obras de engenharia que modificam o sistema fluvial, evitando os prejuízos das inundações) e em não estruturais (de caráter educativo e preventivo) para a sociedade consiga manter uma convivência mais adequada com rio, diminuindo a deterioração decorrente das inundações (C. Tucci, 2003; MINISTÉRIO DAS CIDADES [MCID], 2007).

No Brasil os Planos Diretores devem ser revisados a cada 10 anos, os documentos dos Municípios de Anastácio e 


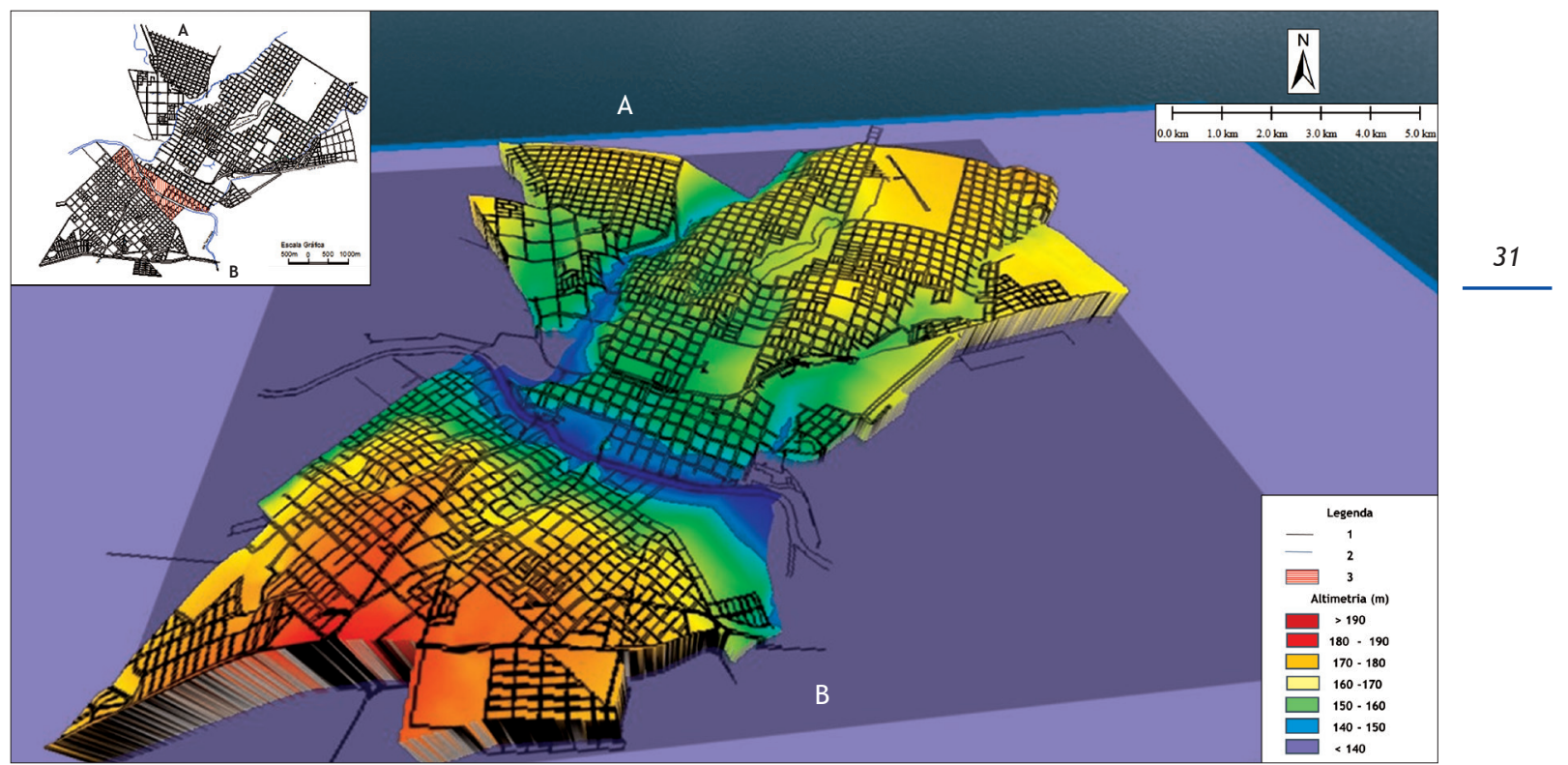

Fig. 6 - Representação planialtimétrica de Aquidauana (A) e Anastácio (B) nos impactos hidrometeóricos:

1) Limite dos municípios; 2) Hidrologia; 3) Áreas suscetíveis à inundação (Fonte: Adaptado pelas autoras, 2016.

Fig. 6 - Planialtimetric representation of Aquidauana $(A)$ and Anastácio $(B)$ in the impacts of climatic hazards: 1) Limits of municipalities; 2) Hydrology; 3) Areas prone to flooding (Source: Adapted by the authors, 2016).

Aquidauana (Prefeitura de Anastácio, 2006 e Prefeitura de Aquidauana, 2008) ainda não foram reavaliados e estima-se que, quando assim o fizerem, devem priorizar a remoção das populações situadas nas áreas de risco. 0 instrumento legal nas duas cidades menciona a situação da população instalada em áreas sujeitas à inundação, porém houve ineficácias de ações em ambas, visto que, nos últimos dezesseis anos, já ocorreram, ao menos, oito situações de inundações de magnitude regular/ média, grande e excepcional, sem que fossem realizadas medidas de evacuar e isolar a área.

Função urbana na planície de inundação do rio Aquidauana nas cidades de Aquidauana e Anastácio

O fluxo de água na seção transversal do canal, ao extravasar em direção ao leito maior, encontra o espaço urbano fragmentado, com diferenciação em sua forma e função (fig. 7). Na área suscetível à inundação, na cidade de Aquidauana, foram identificados 349 lotes e, desses, 240 imóveis com edificações são destinados a unidades familiares, incluindo nessa classificação imóveis mistos, vazios, fechados, abandonados e com destinação turística (fig. 7). Foram também identificadas 38 ativi-dades econômicas, englobando os estabelecimentos fechados, vazios e abandonados, além de 2 chácaras, 59 terrenos baldios, 7 órgãos institucionais, 2 campos de futebol, 1 área paludosa, conhecida popularmente na região como Pirizal, e apenas duas áreas destinadas a Área de Preservação Permanente (APP).
$\mathrm{Na}$ cidade de Anastácio a situação diverge: foram contabilizados 208 lotes, e, desses, 104 imóveis com edificações, abrangendo nessa catalogação imóveis mistos, vazios, fechados, abandonados, destinados a unidades familiares, 9 chácaras e 16 estabelecimentos com fins lucrativos, compreendendo os estabelecimentos fechados, vazios e abandonados (fig. 7). Na área, também foram enumerados 36 terrenos baldios, 16 terrenos com vegetação rasteira, uma área alagada e 10 áreas institucionais que comportam uma instituição assistencial, equipamentos de lazer, entre outros.

A pesquisa sobre função urbana é relevante para - planejamento e gestão ambiental dessas áreas, pois aponta que, principalmente em Aquidauana, na faixa destinada à passagem de inundação, encontrase estabelecida uma concentração expressiva de residências: habitadas, fechadas, vazias, turísticas, mistas e atividades econômicas, como hotéis, clube, lanchonetes. Na coirmã Anastácio o fato mais preocupante está relacionado com a Sociedade Missionária Ebenézer

Some, que é uma instituição assistencial que abriga menores de idade em situação de vulnerabilidade social.

Entende-se que o levantamento de dados das áreas estudadas servirão como ferramenta de apoio para a tomada de ações, por parte do poder público municipal, no sentido de executar os instrumentos legais disponíveis nas duas cidades, como a aplicação de ações institucionais, apropriação dos lotes vazios (terrenos baldios) e impedimento de construção, reforma ou 


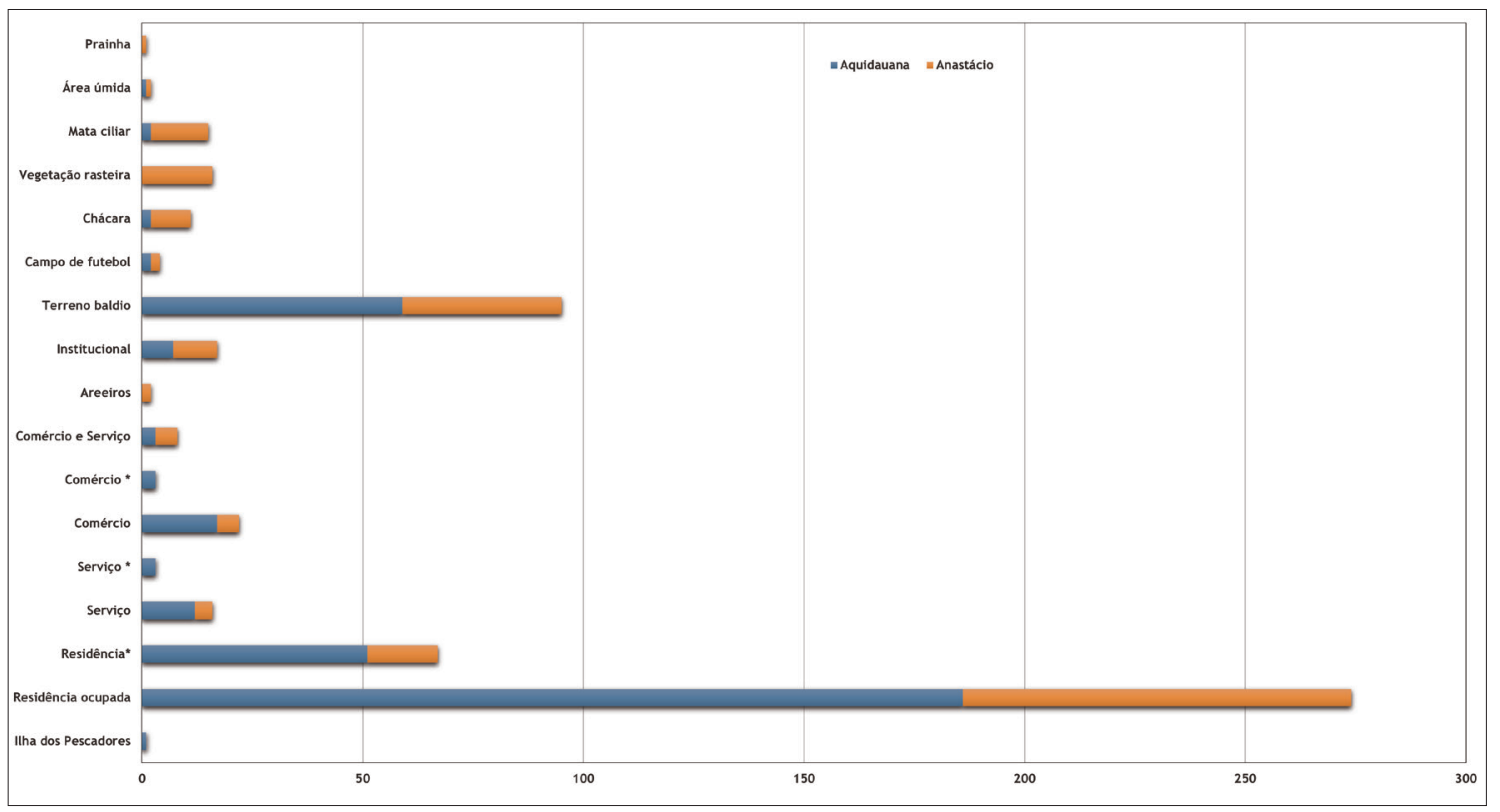

Fig. 7 - Gráfico comparativo da função urbana na área suscetível à inundação das sedes municipais de Aquidauana e Anastácio/MS. * Fechado/vazio/abandonado (Fonte: E. Fernandes, 2015).

Fig. 7 - Comparative graph of urban function in the area prone to flooding of the municipal capitals of Aquidauana and Anastácio/MS. * Source: Closed lempty / abandoned (Source: E. Fernandes, 2015).

ampliação, além de servir como embasamento na aplicação de medidas não estruturais como estratégias educativas junto à população que ocupa esse espaço.

\section{Intensidade de magnitude da Inundação na cidade de Aquidauana}

A partir de janeiro de 1956, na cidade de Aquidauana, em decorrência do loteamento da "Zona Ribeirinha" (planície de inundação do rio Aquidauana), o prejuízo ambiental aumentou consideravelmente (J. Silva e P. Joia, 2001). As visitas in loco evidenciaram que os impactos negativos estão distribuídos por vários locais da planície de inundação, visto que as ondas de cheia têm transportado muito sedimento para as barrancas do rio, que se encontram com graus mínimos de singularidade da vegetação original, interferindo ainda mais na biodiversidade da área que vem sendo ameaçada pelos constantes aterramentos na região do Pirizal e Ilha dos Pescadores.

A dinâmica das inundações sazonais no prelúdio do baixo curso da bacia hidrográfica do rio Aquidauana vem apresentando alterações atribuídas à variabilidade climática regional. 0 canal fluvial, ao atingir a cota máxima de $8 \mathrm{~m}$, na escala hidrométrica, na secção transversal do rio Aquidauana, não comporta a vazão da água e transborda em direção ao seu leito excepcional.

Nessas ocasiões, dependendo da magnitude da inundação, ele atinge trinta e oito estabelecimentos que atuam em atividades comerciais e de serviço (fot. 3), como no episó- dio de março de 2011, quando a Agência Nacional de Águas (ANA) aferiu que o rio encheu mais de $7 \mathrm{~m}$ do seu normal.

Inerente a esta área, imóveis totalmente inseridos na APP. Em um trecho de aproximadamente $100 \mathrm{~m}$ estão estabelecidos um hotel de médio porte, muito frequentado por turistas, um trailer de lanche, a Câmera de Vereadores e dois clubes de lazer, todos nas adjacências da Ponte Roldão Carlos de Oliveira, conhecida popularmente como Ponte Velha.

Os custos na recuperação de imóveis atingidos regularmente pelas inundações sazonais contribuem para que, na área, sejam contabilizados 59 terrenos baldios, 51 residências e 6 atividades econômicas fechadas, abandonadas ou vazias, fato que se supõe estar relacionado à recorrência de inundação durante cinco anos consecutivos (2010, 2011, 2012, 2013 e 2014).

Em relação ao episódio de impacto hidrometeórico do mês de março de 2011, a topografia da área favoreceu que fossem atingidas, entre a área central e o bairro Guanandy, 187 residências ocupadas (particulares ou para fins turísticos).

Os órgãos institucionais que funcionam na área suscetível à inundação tiveram suas atividades suspensas, entre eles as três Estações de Tratamento de Esgoto (ETEs), que foram totalmente inundadas, prejudicando a função urbana da planície de inundação na margem direita da sede municipal de Aquidauana. As atividades econômicas foram atingidas em trinta e um estabelecimentos, 
ficando inoperantes por aproximadamente quinze dias, e outras unidades trabalharam com quadro de funcionários reduzido, alterando o cotidiano na cidade.

$\mathrm{Na}$ área central, o caos se instalou devido ao bloqueio das duas pontes de acesso à cidade. Contudo, no bairro Guanandy, os transtornos repercutiram por toda a circunvizinhança, visto que houve a necessidade de interditar trecho da Rua Cândido Mariano e o funcionamento da Escola Estadual Cândido Mariano, para abrigar parte da população atingida (fot. 4).

A intensidade dos impactos hidrometeóricos relacionase principalmente com a intensidade da magnitude do evento e com o grau de vulnerabilidade ao qual o ecossistema encontra-se exposto. A associação destes fatores gera um risco maior ou menor à população estabelecida naquela área.
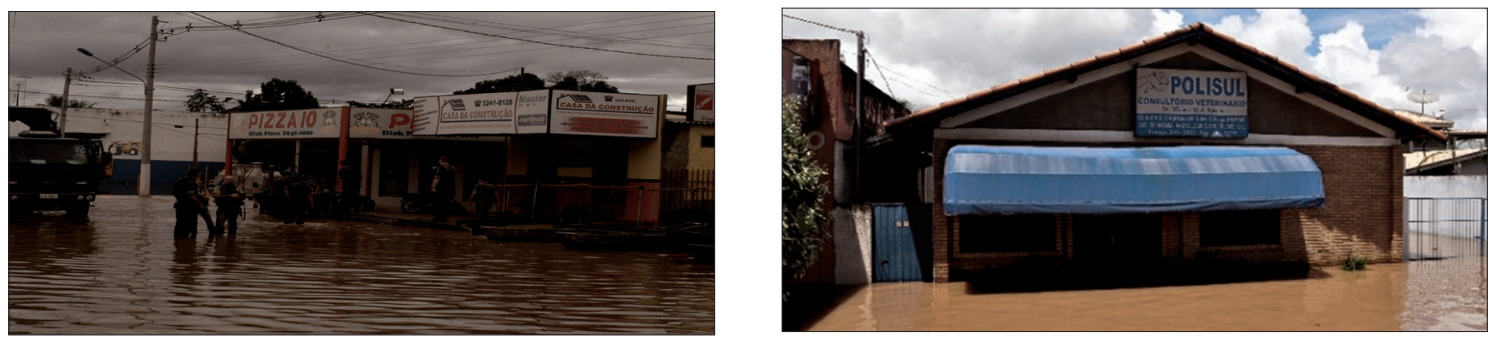

Fot 3 - Atividades comerciais atingidas em inundações de magnitude excepcional (Fonte: Arquivo pessoal da família Moro, 2011).

Photo 3 - Business activities hit by floods of exceptional magnitude (Source: Sirnay Moro, 2011).
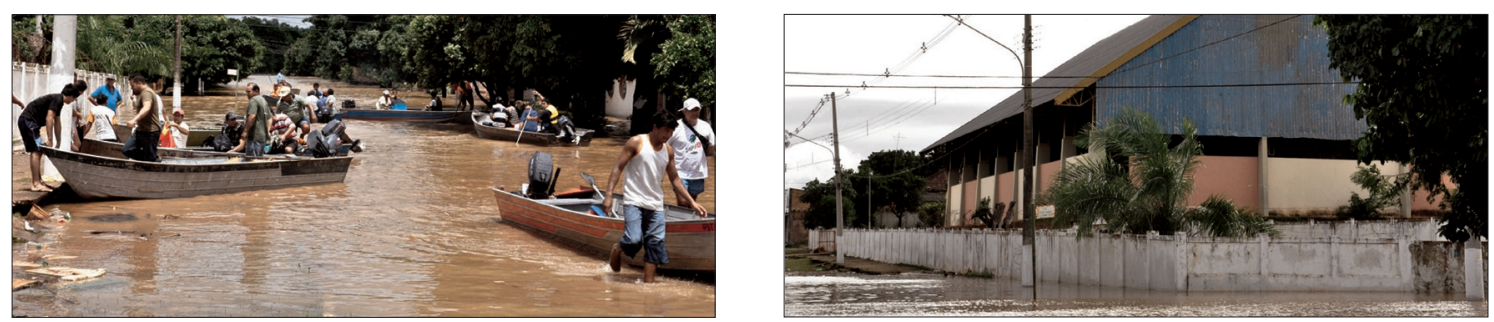

Fot. 4 - Intensidade do impacto hidrometeórico na cidade de Aquidauana no mês de março de 2011 (Fonte: S. Moro, 2011 ).

Photo 4 - Intensity of the hydrometric impact on the city of Aquidauana in March 2011 (Source: S. Moro, 2011).
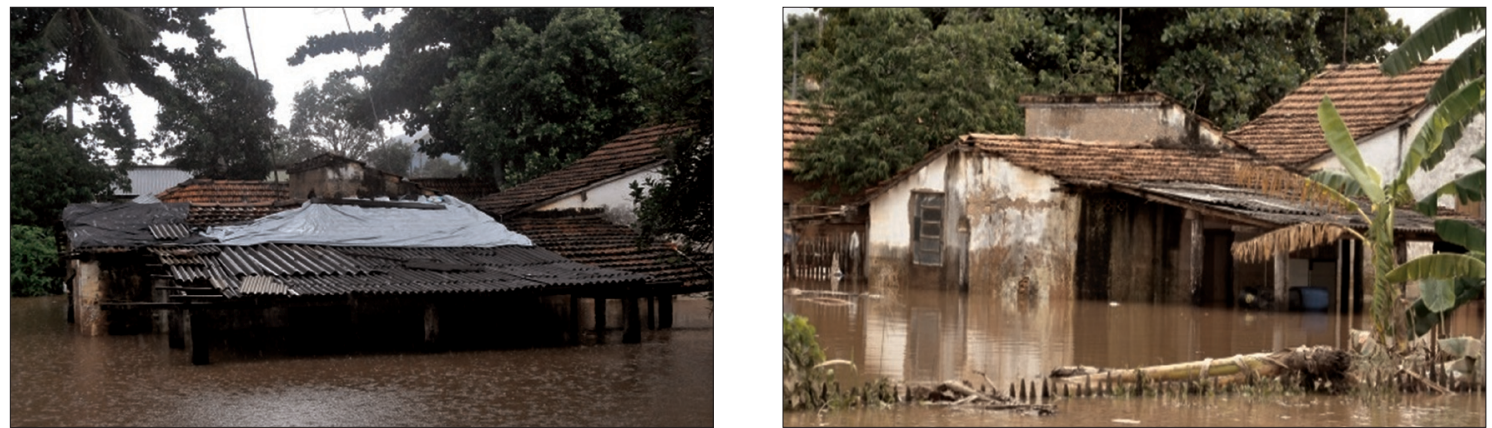

Fot. 5 - Vulnerabilidade das residências atingidas sistematicamente pelas inundações na cidade de Aquidauana/MS (Fonte: V. Rezende/Correio do Estado, 2016).

Photo 5 - Vulnerability of the households systematically affected by floods in the city of Aquidauana /MS (Source: V. Rezende/Correio do Estado, 2016). 
de maneira mais severa sobre o talude, visto que o ambiente se encontra reconfigurado.

Intensidade de magnitude da Inundação na cidade de Anastácio

O território que atualmente compõe o município de Anastácio foi desmembrado de Aquidauana no final da década de 1960. Em 1892, época da fundação do vilarejo de Aquidauana e durante o início do século XX, foi extremamente relevante para o crescimento econômico da então recém Vila Alto Aquidauana (J. Neves, 2007). Durante muito tempo, a margem esquerda foi preservada da supressão vegetal, pelo fato do crescimento demográfico ter se manifestado de maneira mais expressiva na margem direita, e os grandes terrenos, mais parecidos com chácaras, terem permanecidos preservados (J. Silva, 2009).

A reprodução do espaço urbano na cidade de Anastácio distingue-se pela disparidade de suas formas, funções, interações e práticas espaciais. Essa divergência do espaço é, em realidade, um reflexo e uma condição para as políticas públicas (R. Corrêa,1989).

O Poder Público municipal, na margem esquerda do rio, como agente modelador do espaço, destinou parte da área suscetível à inundação à implantação de infraestrutura de lazer: praia semiartificial, praças esportivas e de eventos, o que minimiza os reflexos da inundação para os citadinos. Contudo, a Sociedade Missionária Ebenézer - Some - Unidade de Acolhimento e Proteção à Criança e ao Adolescente, que está localizada na barranca do rio Aquidauana, é afetada severamente nos casos de inundações grandes e excepcionais. Em média, vinte pessoas ficam desalojadas e têm sérios prejuízos econômicos (fot. 6).

$\mathrm{Na}$ malha urbana da sede municipal de Anastácio os reflexos são percebidos a partir da magnitude regular/média das inundações. Quando as águas do rio Aquidauana atingem a elevação superior a 141,2 m de altitude, 527.407,64 $\mathrm{m}^{2}$, a cidade pode ser atingida, como ocorreu em março de 2011.

Na sede municipal de Anastácio, a dinâmica de ocupação do espaço foi predisposta de maneira que a várzea do rio permanecesse em sua maior parte com APP, apesar da presença de atividades institucionais, comércio e serviço: pesqueiro, um estaleiro, dois areeiros, três estruturas de Estação de Tratamento de Esgoto (ETE) e a guarnição do $1^{\circ}$ Subgrupamento de Bombeiros.

Percebe-se que os problemas que afligem a população, nas duas localidades, relacionados à inundação, poderiam ser atenuados se o uso da planície de inundação estivesse respeitando o novo Código Florestal (Governo Federal, 2012).
Os atores sociais envolvidos na remodelagem do espaço na área de várzea do rio Aquidauana (promotores imobiliários e Estado) primaram por não lotear toda a margem, preservando a mata ciliar em diversos pontos, porém as inundações mais expressivas atingem a população menos favorecida que reside nas áreas de topografia suave.

\section{Conclusão}

O estudo revela que a intensidade de magnitude das inundações que assolam a comunidade está diretamente relacionada com o excesso pluviométrico na área da bacia hidrográfica do rio Aquidauana e a desorganização da expansão territorial urbana. Esses fatores aliamse à ineficiência do planejamento e gestão ambiental e, desde a fundação do povoado do Alto Aquidauana, contribuíram para que as intervenções dos agentes sociais produtores do espaço, sobretudo a partir da década de 1950, estimulassem a ocupação de áreas de risco. Isso potencializou o uso da borda da bacia de inundação do canal fluvial, que é cortado, nessa secção transversal, pelas cidades de Aquidauana e Anastácio.

Observa-se que há preferência dos indivíduos por se estabelecerem em espaços residenciais próximos das localidades da área central. Para a população mais carente, essa é uma forma de status, pois está fora da periferia das cidades. Contudo, por conta da acumulação de capital, dividido de maneira desigual, a diferença de impactos hidrometeóricos sofridos pela sociedade é variada, atingindo violentamente as residências mais vulneráveis das classes menos favorecidas.

A topografia da área de estudo foi o parâmetro que melhor respondeu à escala do trabalho, para determinar as áreas suscetíveis à inundação, considerando-se o relevo suave. A delimitação da área atingida nos impactos hidrometeóricos respalda o zoneamento para a planície de inundação das duas cidades, e deveria constar nos Planos Diretores de cidades que convivem com a problemática de inundações ribeirinhas (C. Tucci, 2003).

Os danos humanos, materiais e ambientais e prejuízos econômico-sociais que acompanham os impactos hidrometeóricos necessitam ser absorvidos por ações governamentais. "A tomada de decisão está comumente ligada à política administrativa para expressar noção mais coletiva de escolhas e comportamentos nos altos níveis de gerenciamento de recursos cujas ações objetivam medidas emergenciais, preventivas e corretivas a dado evento prejudicial" (White, 1974, p.6).

Os atores sociais envolvidos na problemática das inundações permanecem inertes diante dos constantes transbordamentos do rio Aquidauana. Infere-se que, por este estudo, o delineamento realizado da área suscetível à inundação das cidades de Anastácio e Aquidauana 

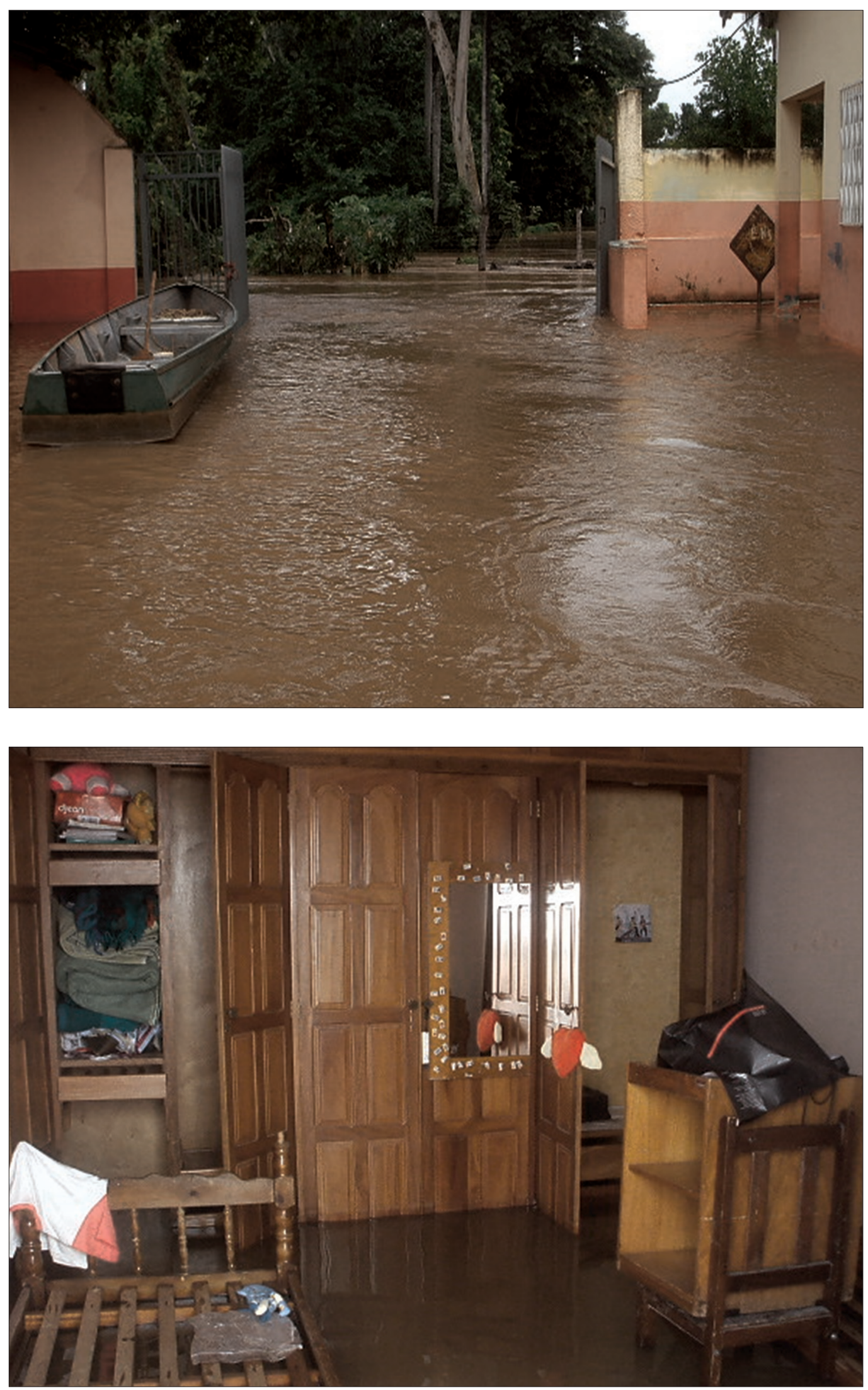

Fot. 6 - Instituição Some afetada severamente nas inundações em Anastácio (Fonte: Arquivo pessoal da família Souza, 2011). Photo 6 - Some institution severely affected by floods in Anastácio (Source: Personal Archive of the Souza Family, 2011). 
colabore como instrumentos básicos de suporte para ação da Defesa Civil, contribuindo para o início do processo de remodelagem da área.

Os agentes sociais que modelaram os dois perímetros urbanos (os proprietários dos meios de produção, proprietários fundiários e os promotores imobiliários) atuaram em função de diferentes estratégias sobre esse espaço urbano, o que acarretou em conflitos de interesses.

O estudo sugere a remoção da instituição assistencial Some, situada na cidade de Anastácio, a implementação de pisos permeáveis no entorno das margens, e, nas ruas que se encontram sem pavimentação, nas duas cidades. Será necessário optar por medidas estruturais extensivas (C. Tucci, 2003), que afetariam o sistema hidrológico, mas não teriam intervenção direta sobre o canal. É necessária a conscientização, por parte do poder público nas suas diversas esferas, da relevância ao incentivo de medidas que fomentem iniciativas de preservação e recuperação das matas ciliares.

Acredita-se que, em Aquidauana, a restrição total para construção e a fiscalização dos aterramentos na margem devem ser medidas acatadas imediatamente pelo poder público, juntamente com a revisão do Plano Diretor (2008) que, no ano de 2018, completará dez anos e está passível de revisão.

O Estado, que é o agente regulador do uso e ocupação da terra nesse processo, tem se mostrado ineficaz na organização espacial das cidades de Anastácio e Aquidauana, fazendo juz ao "obstáculo econômico $e$ político dos governantes” (M. Souza, 2010).

Percebe-se a subutilização ou negligência de ações que poderiam ser empregadas por parte das duas administrações municipais: implantação de infraestrutura adequada (drenagem, ampliação da rede de esgoto), desapropriação de terras, regulamentação do uso da terra, controle e limitação da superfície, taxação de terrenos livres, por meio do IPTU Progressivo (M. Souza, 2010 a).

Nas sedes municipais de Anastácio e Aquidauana, a expansão da malha urbana, associada ao preço da terra, nas últimas décadas, instigou a procura por terrenos mais baratos na área de passagem de inundação, assim como aluguéis compatíveis com a baixa renda da maioria dos trabalhadores estabelecidos nas duas cidades. Os moradores desse espaço vêm se tornando reféns da sua própria tragédia, pois, estabelecidos na área suscetível a impactos hidrometeóricos, muitas vezes perdem todos os seus pertences, mas, mesmo assim, consideram compensatório, pois as pessoas querem morar em locais mais próximos do centro da cidade, e acabam achando, nesse ambiente, preços acessíveis ao seu orçamento financeiro.

Os problemas concernentes às inundações vêm se intensificando na década de 2010 no alfa do Pantanal sul- mato-grossense brasileiro, atingindo as sedes municipais de Anastácio e Aquidauana. Revela-se uma acentuada diminuição do tempo de recorrência das inundações, devido à dinâmica hidrológica natural que acompanhou os excessos pluviométricos. Nas áreas suscetíveis a impactos hidrometeóricos, são inevitáveis os danos materiais e os prejuízos econômicos e sociais, por conta das ações humanas inadequadas. A apropriação da natureza, o desrespeito às leis ambientais vigentes (Governo Federal, 2012), o loteamento das áreas e a agregação de instalações vulneráveis colaboram com a produção de risco e crises cada vez mais acentuadas.

\section{Referências bibliográficas}

Alexander, David E. (2013) - A survey of the field of hazard and disaster studies. Journal of Civil Engineering and Architecture, [online]. 7 (7), p. 841- 853.

Alcántara-Ayala, Irasema (2002). Geomorphology, natural hazard, vulnerability and prevention of natural disasters developing countries. Geomorphology, 47 (2), p.107-124.

ANA - AGÊNCIA NACIONAL dE ÁGUAS (2016). Hidro web. Sistema de informações hidrológicas. Disponível em: http://hidroweb.ana.gov.br/. Acesso em 14 de março de 2016.

Artigas, Elvis F.; Loubet, Elaine N.; Andrade, Vicentina S. da A. (2012). Inundações e riscos na cidade de Aquidauana-MS. Territorium, [online] v. 19, p.5562. Disponível em: http://www.uc.pt/fluc/nicif/ riscos/Documentacao/Territorium/T19_artg/T19_ Artigo_07.pdf. Acesso em: 12 de janeiro de 2015.

Corrêa, Roberto L. (1989). O espaço urbano. Editora Ática, Sâo Paulo (Séries Princípios), 94 p.

Da Silva, Vanessa A. ( 2012). O clima local de Aquidauana (Monografia Bacharel em Geografia). Universidade Federal de Mato Grosso do Sul, Aquidauana, 65 p.

Duarte, Aluízio C. (1988). O Centro-Oeste na Organização Regional do Brasil. In: Instituto Brasileiro de Geografia e Estatística/ IBGE. - Geografia do Brasil, Região Centro-Oeste. Rio de Janeiro, IBGE (vol.1); p.15-20.

ESTRATÉGIA INTERNACIONAL PARA LA REDUCCIÓN DE DESASTRES LAS AMÉRICAS/ EIRD/ONU (2004) - Terminologia. [para.18]. Disponível em: http://www.eird.org/esp/ terminologia-esp.htm. Acesso em: $18 \mathrm{de} \mathrm{dez.} 2014$.

Fernandes, Elvira F. De L.; Anunciação, Vicentina S. da; Silva, Jaime F. da ( 2015, 07, 27). Vulnerabilidade Socioespacial na Planície de Inundação na cidade de Aquidauana/MS - Brasil. Territorium, [online], (n. ${ }^{\circ}$ 22), p.177- 194. Disponível em: http://www.uc.pt/ fluc/nicif/riscos/Documentacao/Territorium/T22 Artg/T22_Artg14.pdf. Acesso em 21 de maio de 2016. 
Fernandes. Elvira F. de L. (2015). Representação socioespacial no baixo curso do Rio Aquidauana: estratégias educativas para gestão de desastres naturais (Dissertação Mestrado em Geografia). Aquidauana, Universidade Federal de Mato Grosso do Sul, 115p.

Google. Imagens Google Earth. 2014. Anastácio.

Google. Imagens Google Earth. 2014. Aquidauana.

GOVERNO DO ESTADO DE MATO GROSSO DO SUL (2011). Projeto GeoMS: Cobertura vegetal e uso da terra do Estado de Mato Grosso do Sul, João dos Santos Vila da Silva [et al.]. Campinas: Embrapa Informática Agropecuária.

GOVERNO FEDERAL (1964-1966). DSG. Diretoria do Serviço Geográfico do Exército. Cartas topográficas. Escala 1:100.000. Aquidauana - Folha SF. 21-10-A-III. - DSG, Rio de Janeiro.

GOVERNO FEDERAL (2012). Lei n 12.651 (2012). Dispõe sobre a proteção da vegetação nativa; altera as Leis $\mathrm{n}^{\text {os }} 6.938$, de 31 de agosto de 1981, 9.393, de 19 de dezembro de 1996, e 11.428, de 22 de dezembro de 2006; revoga as Leis $n^{\text {os }} 4.771$, de 15 de setembro de 1965, e 7.754, de 14 de abril de 1989, e a Medida Provisória n².16667, de 24 de agosto de 2001; e dá outras providências. Diário Oficial [da] República Federativa do Brasil, - DF: Congresso Federal, 28 de mai. 2012. Disponivel em: http://www.planalto.gov.br/ccivil_03/_ato20112014/2012/lei/l12651.htm. Acesso em 15 de mar. 2015.

Guidicini, Guido; Nieble, Carlos. (1976). Estabilidade de taludes naturais e de escavação. São Paulo, Edgard Blücher.

Hoffmann, Teresa C. P.; Mendonça, Francisco; Goudard, Gabriela (2014). Eventos climáticos extremos: inundação e gestão de riscos no Paraná. In: Mendonça, Francisco (Org.). - Riscos Climáticos: Vulnerabilidade e resiliência associados. Paco Editorial, Jundiaí (1.ed.); p.223 - 260.

Honorato, Ana Flávia A. (2012). Identificação de ilhas de calor e frescor na cidade de Aquidauana/MS. (Monografia Bacharel em Geografia). Universidade Federal de Mato Grosso do Sul, Aquidauana, 65 p.

INSTITUTO BRASILEIRO DE GEOGRAFIA E ESTATÍSTICA/ IBGE (2010) - Cidades@. Mato Grosso do Sul. Anastácio. Disponível em: http://cidades.ibge.gov.br/xtras/perfil.php?lang=\& codmun=500070\&search=mato-grosso-do-sul $\mid$ anastacio . Acesso em: 19 de fevereiro de 2016.

INSTITUTO BRASILEIRO DE GEOGRAFIA E ESTATÍSTICA/ IBGE (2010) - Cidades@. Mato Grosso do Sul. Aquidauana. Disponível em: http://cidades.ibge.gov.br/xtras/ perfil. php?lang=\& codmun=500110\& search=ma to-grosso-do-sul|aquidauana. Acesso em: 19 de fevereiro de 2016.

INSTITUTO BRASILEIRO DE GEOGRAFIA E ESTATÍSTICA/ IBGE (2010a). Sinopse por setores. Disponível em: http://www.censo2010.ibge.gov.br/sinopseporsetores/. Acesso em 27 de julho de 2015.

INSTITUTO NACIONAL DE METROLOGIA - INMET (2015). Estações e Dados. Estação Aquidauana A - 719. Disponível em: http://www.inmet.gov.br/portal/. Acesso em: $10 \mathrm{de}$ março de 2016.

Lucas, Taíza de P. B.; Augusto, Pollyanna; REIS, Stefany dos; Rocha, Solimar Carnavalli (2015). Impactos Hidrometeóricos em Belo Horizonte-MG, Revista Brasileira de Climatologia, Curitiba [Eltronica], (v. 16), p. 7 - 28. Disponivel em: http://revistas. ufpr.br/revistaabclima/article/view/37051/25982. Acesso em 30 de maio de 2016.

Manning, John C. (1997). Applied Principles of Hydrology. Hydrology. Prentice Hall, Nova Jersey (EUA) ( $3^{\mathrm{a}}$ ed.); 276 p.

MINISTÉRIO DA CIÊNCIA, TECNOLOGIA INOVAÇÃO E COMUNICAÇÕES - MCT / INSTITUTO NACIONAL DE PESQUISAS ESPACIAIS - INPE/CPTEC (2011). Boletim de Monitoramento e Análise Climática, Brasil, Climanálise [online] (v. 26), $\mathrm{n}^{\circ}$ 03. Disponível em: http://climanalise.cptec.inpe. $\mathrm{br} /$ rclimanl/boletim/pdf/pdf11/mar11.pdf. Acesso em: 30 de março de 2015.

MINISTÉRIO DAS CIDADES/CITIES ALLIANCE (2006). Mapeamento de Riscos nos Municípios. In: Celso Santos Carvalho e Thiago Galvão ( Org. ). - Prevenção de Riscos de Deslizamentos em Encostas: Guia para Elaboração de Políticas Municipais. Ministério das Cidades; Cities Alliance, Brasília; p.46 -55.

MINISTÉRIO DAS CIDADES / INSTITUTO DE PESQUISAS TECNOLÓGICAS IPT (2007). Mapeamento de Riscos em Encostas e Margem de Rios / Carvalho, Celso Santos; Macedo, Eduardo Soares de; Ogura, Agostinho Tadashi (Org.). Brasília: Ministério das Cidades; Instituto de Pesquisas Tecnológicas (IPT). Disponível em: http://www.cidades. gov.br/images/stories/ArquivosSNPU/Biblioteca/ PrevencaoErradicacao/Livro_Mapeamento_Enconstas_ Margens.pdf. Acesso em 12 de janeiro de 2015.

MINISTÉRIO DAS CIDADES/INSTITUTO NACIONAL DE PESQUISAS ESPACIAIS (2011). Desastres Naturais e Geotecnologias: Conceitos básicos. [publicação interna]. Disponível em: http://mtc-m16d.sid.inpe.br/col/sid.inpe.br/ mtc-m19/2011/11.16.18.05/doc/publicacao.pdf. Acesso em 16 de março de 2016.

MINISTÉRIO DO MEIO AMBIENTE (1997) - Mapa de Áreas Inundáveis - Aquidauana. In: Plano de Conservação da Bacia do Alto Paraguai (PCBAP-IPH/UFGS). Programa Nacional de Meio Ambiente (PNMA).

Monteiro, Carlos A. de F. (2015). A Climatologia Geográfica no Brasil e a Proposta de um Novo Paradigma. In: Monteiro, Carlos A. de F. (Org.) - A Construção da Climatologia Geográfica no Brasil, Alínea, Campinas; p.61 - 153.

Moro, Sirnay (2011). Prefeitura de Aquidauana. Inundação 2011. 
Neves, Joana (2007). Um porto para o Pantanal: a fundação de Aquidauana, civilização e dependência. Universidade Federal de Mato Grosso do Sul (UFMS), Campo Grande,155p.

Olcina Cantos, Jorge; Hernández Hernández, M.; Rıco Amorós, A.M.; MARTínez Ibarra, Emilio/ Natural Hazards and Earth System Sciences (2010). Increased risk of flooding on the coast of Alicante (Region of Valencia, Spain), [on line]. Disponível em: http://www. nat-hazards-earth-syst-sci.net/10/2229/2010/. Acesso em 15 de junho de 2015.

PLANO DIRETOR (2006) - Lei Complementar nº 017/2006, Prefeitura Municipal de Anastácio. Diário Oficial [do] Estado de Mato Grosso do Sul. Anastácio. 62 p.

PLANO DIRETOR (2008) - Lei Complementar nº 009/2008, Prefeitura Municipal de Aquidauana. Diário Oficial [do] Estado de Mato Grosso do Sul. Aquidauana. 62 p.

PREFEITURA DE AQUIDAUANA (2015). Lei Ordinária n. ${ }^{\circ}$ 2.390/2015. Dispõe sobre o Abairramento do Distrito-Sede do Município de Aquidauana, e dá outras providências. Disponível em: http://www. aquidauana.ms.gov.br/DOEM/DOEM_AQUIDAUANA-250-20150310.pdf. Acesso em 07 de set.de 2015.

Rezende, Valdenir (2016). Correio do Estado. Disponível em: http: / /www.correiodoestado.com.br/ cidades/chuva-continua-causando-estragos-esobe-numero-de-cidades-em/268040/. Acesso em 25 de março de 2016.

Sant'Anna Neto, J. Lima (1989) - Algumas considerações sobre a dinâmica climática da porção sudeste do Pantanal Sul-mato-grossense. Boletim Paulista de Geografia, São Paulo, (n. ${ }^{\circ}$ 67), p.75-88.

Santos, Flávio C. dos (2014). Estudo da temperatura do ar nas cidades de Aquidauana e Anastácio-MS (Dissertação de Mestrado em Geografia). Universidade Federal de Mato Grosso do Sul, Três Lagoas, 157 p.
Silva, Jaime F. da; Joia, Paulo R. (2001) Territorialização e Impacto Ambiental: Um estudo da Zona Ribeirinha de Aquidauana-MS. Revista Pantaneira, Aquidauana, v. $3, \mathrm{n}^{\circ} 1, \mathrm{p} .17-30$.

Silva, Jaime Ferreira da (2009). Territorialização e Impacto Ambiental Anastácio - MS. Revista Pantaneira, Aquidauana, volume 11, $\mathrm{n}^{\circ} 1, \mathrm{p} .13-27$.

Souza, Marcelo Lopes de (2010). ABC do desenvolvimento urbano. Rio de Janeiro, Bertrand Brasil (5 $5^{\mathrm{a}}$ edição), $192 \mathrm{p}$.

Souza, Marcelo Lopes de (2010a). Mudar a cidade: Uma Introdução Crítica ao Planejamento e a gestão Urbanos. Rio de Janeiro. Editora Bertrand Brasil ( $5^{\mathrm{a}}$ edição), 556 p.

Tucci, Carlos E. M. (2003). Inundações e Drenagem Urbana. In: Tucci, Carlos E. M. e Bertoni, J. Carlos (Org.) - Inundações urbanas na América do Sul. Associação Brasileira de Recursos Hídricos, Porto Alegre; p.45-129.

Valeriano, M. M. (2008). TOPODATA: guia de utilização de dados geomorfométricos locais. São Jose dos Campos: INPE, 44p.

White, Gilbert F. (1974). Natural Hazards: Local, Nacional, Global. New York, Oxford University Press USA, 288 p.

Zamparoni, Cleuza A. G. Pereira; Nunes, Lucí H. (2012) - Desastres naturais de origem atmosférica e seus impactos em Moçambique. In: Guimarães, Solange T.; Carpi JR., Salvador; Godoy, Manoel B.R.B.; Tavares, Antônio C. (Org.). - Gestão de áreas de riscos e desastres ambientais. IGCE/UNESP/RIO CLARO/Programa de Pós-Graduação em Geografia, Rio Claro (vol. 1); p.375 - 404.

Zavattini, João. A. /Editora UNESP (2009). As chuvas e as massas de ar no estado de Mato Grosso do Sul: estudo geográfico com vista à regionalização climática [online]. Disponível em: http://static.scielo.org/ scielobooks/qx8r5/pdf/zavattini-9788579830020.pdf. Acesso em: 20 de março de 2016. 